\title{
Electrical Machines for the More Electric Aircraft: Partial Discharges Investigation
}

\author{
Vincenzo Madonna, Member, IEEE, Paolo Giangrande, Senior Member, IEEE, and, \\ Michael Galea, Senior Member, IEEE
}

\begin{abstract}
Modern electrical machines employed in transportation applications are required to provide high performance in terms of power (and torque) density. At the same time, being these applications safety-critical, a significant level of reliability and/or fault tolerance is expected. Among all the factors which can compromise motors reliability, partial discharges inception is one of the most crucial, in particular for low voltage, random wound machines. This paper presents an extensive experimental investigation on partial discharges in electrical machines for aerospace applications. Measurements are carried out using both sinusoidal and fast-rising pulses in a representative aerospace environment, emulating the typical ambient conditions encountered throughout a commercial aircraft mission, and beyond (i.e. down to 30 mbar). As a main result of the investigation, it is proved that electrical machines employed for actuating primary flight control surfaces feature a higher risk of partial discharges inception. Therefore, their insulation system demands an extremely careful design.
\end{abstract}

Index Terms - Electrical Machines Design, Partial Discharges, Reliability, Organic Insulation, Aerospace

\section{INTRODUCTION}

厂 nsulation related problems represent one the main causes leading to premature failures in electrical machines. The adoption of modern variable speed drives has been widely recognised, by the scientific community, as one of the primary reasons of machines' insulation over-stress [1-3]. The combination of fast switching devices (i.e. high $\mathrm{dV} / \mathrm{dt}$ ) and long cables between power electronics converter and machine can cause non-negligible overvoltage at the motor side [4]. Low voltage machines (i.e. rated voltage $<700 \mathrm{Vrms}$ ) are commonly manufactured using Type-I insulation (i.e. organic chemical composition). Organic insulating materials do not have the ability to withstand partial discharges (PD), which are electrical discharges that only partially bridge the insulation between electrical conductors. These discharges, despite being low energetic phenomena, might cause the machine's out-of-service within few hours/days after their repetitive inception. Therefore, Type-I-insulated motors should be designed to be PD-free throughout their whole lifetime. Despite this criticality, organic-insulated machines are largely adopted in a wide range of applications, some of which are safety-critical (e.g. aerospace

V. Madonna, P. Giangrande and M. Galea are with the Power Electronics, Machines and Control Research Group (PEMC), University of Nottingham, UK. M. Galea is also with the Key Laboratory of More Electrical Aircraft Technology of Zhejiang Province, Ningbo, China. Corresponding Author: V. Madonna(Vincenzo.Madonnal@nottingham.ac.uk).

This work was funded by the Propulsion Futures Beacon of Excellence at the University of Nottingham, UK.

This project has also received funding from the Clean Sky 2 Join Undertaking under the European Union's Horizon 2020 research and innovation programme under grant agreement no. 807081 . and automotive) [5, 6], including in the so-called 'more electric aircraft' (MEA).

The MEA initiative, aims at replacing and / or complementing conventional secondary on-board power systems (e.g. hydraulic and pneumatic) through electricallypowered counterparts. Electric drives for the MEA need to have extremely low failure probability, given the safety-critical nature of the application. Nonetheless, the adoption of 'over-protective measures' (e.g. use of thicker insulating materials), while positively influencing reliability, might negatively affect the electromechanical energy conversion performance (e.g. torque and power densities) [7]. This means that a precise understanding of the insulation system's behaviour in terms of PD inception during actual operation is crucial for guaranteeing the simultaneous fulfilment of reliability and power density constraints. Various investigations have been carried out on PD analysis for insulation systems of Type-I machines [2, 8, 9], although only few of them refer to motors for aerospace applications [10-12]. In [10], an innovative 'contactless' PD detection method for machines' insulation is proposed, and its suitability is verified in a representative aerospace environment, down to 100 mbar pressure. On the other hand, in [11] the authors mainly focus on modelling the PD phenomenology through the Paschen's law, with experiments carried out on round enamelled magnet wire specimens. Similarly, in [12] the authors address PD modelling in partial vacuum, although a different approach is adopted for evaluating the PD inception phenomenology, which is based on the streamer criterion. In [12], tests are carried out in representative aerospace environment, with pressures down to 200 mbar.

Although there is an increasing wealth of research now available on the understanding of physical phenomena related to PD inception in machines' insulation systems, all these works usually stop at 'describing' these phenomena from a dielectric science perspective. What is virtually non-existent today are the processes on how these important analyses would fit in the practical design of electrical machines. This work tries to fill this research gap, by combining elements of dielectrics science together with practical considerations on electrical machines design, by focusing on aerospace applications. The presented analyses, derived from extensive PD measurements in representative aerospace environment, can help machine designers, manufacturers and policy makers in identifying which are the most critical machines within a MEA. In a more detailed fashion, the main technical contributions and novelties of this paper are the following:

1. The identification of the specific operating environment (i.e. temperature and pressure) for all the main electrical machines within a MEA;

2. The presentation of experimentally measured PD datasets (i.e. inception voltage) on motor winding specimens, carried out in representative aerospace 
environment, adopting both sinusoidal and square waveform excitation;

3. The identification of the most critical machines within a MEA, that are highly likely to be exposed to PD inception when in operation;

4. The analysis of additional factors, apart from ambient pressure (i.e. altitude), which can influence the inception of PD in machines insulation, namely, temperature, thermal aging and difference between PD inception voltage and extinction voltage (i.e. hysteresis effect).

The paper is organised as follows: Section II provides an introduction regarding various machines encountered in a MEA, together with their typical operating environment throughout a flight mission. In Section III, the voltage amplification problem, caused by modern power converters, is discussed. Section IV gives a brief overview on the Paschen's law and its applicability in modelling the PD inception in motors' insulation systems. The core of the investigation is carried out in Section V and VI, where the experimental results are analysed. Finally, Section VII provides a discussion regarding the impact of PD on the design of insulation for aerospace machines.

\section{ELECTRICAL MACHINES IN THE MEA}

This Section serves as a general background regarding the various machines encountered in a MEA and their typical operating environment. These data, which are critical for understating the whole problematic analyzed in this work, will be re-called in the final discussion of Section VII.

One of the key elements at the basis of any electrification programme is the electric drive. That is, the combination between a machine, whose speed/position is regulated through a suitably controlled power electronics converter. In a MEA, converters feeding organic-insulated (i.e. Type-I) machines can be employed for various purposes, including: 1) Actuation for primary and secondary flight control surfaces; 2) Landing gear actuation (extension / retraction and steering); 3) Aircraft taxiing; 4) Compressors and fans for the environmental control system; and 5) Fuel and fluid pumps.

Whilst the insulation system construction for these machines can be very similar, their operating environment is not. In fact, a number of these motors operate in a pressurized, controlled environment (i.e. cabin or cargo bay), while others are installed and/or operate in unpressurised sections of the aircraft.

The typical primary and secondary flight control surfaces in a mid-sized commercial aircraft are shown in Fig. 1. In a MEA, the machines actuating these flight control surfaces need to be installed next to the actuator pivot, and thus in an unpressurised section of the aircraft. Primary flight control surfaces allow the aircraft's maneuverability at any flight stage, meaning that their prime mover can be potentially operated at any altitude (i.e. pressure). On the contrary, secondary control surfaces are needed for increasing the wings' lift, allowing the aircraft to fly at lower speed. Hence, these are generally activated at a relatively lower altitude, with respect to their primary counterparts. According to the Boeing 737's operating manual (i.e. most produced jet airliner), the flaps (i.e. secondary surface) should only be operated below $6 \mathrm{~km}$ (i.e. $\approx 20,000$ feet). This can be roughly considered as a baseline operational limit for secondary flight control surfaces in a MEA.

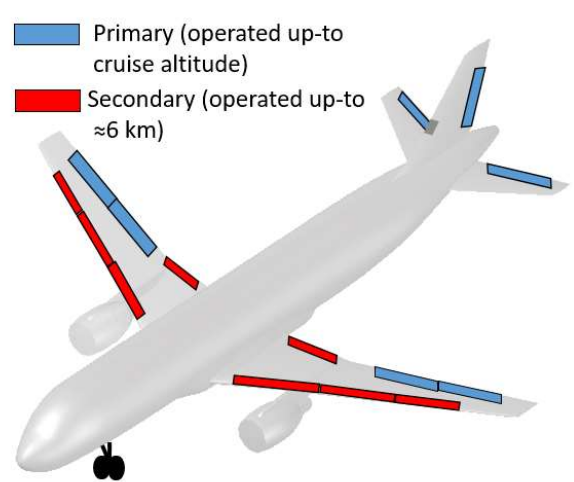

Fig. 1. Main flight control surfaces in a typical mid-sized aircraft.

Similarly to secondary flight control surfaces, the landing gear is extended shortly after taking-off and just before landing. It is thus fair assuming that the motor actuating the landing gear mechanism is operated slightly above ground level. Here it is important to note that "ground level" does not mean that the machine is operated at sea level pressure, but its activation altitude will mainly depend on the airport location. For this reason, the altitude above sea level of more than 3,900 amongst the busiest airports in the world has been analysed [13], and the outcome is summarized in Fig. 2, where the airports' altitudes are clustered and shown as a histogram plot. In Fig. 2, the eight of the bars represents the number of airports whose altitude above sea level lies within the ranges reported in abscissa. Clearly, most airports are located slightly above sea level altitude. This indicates that the variation in operating pressure is not a design constraint for the insulation system of landing gear actuation motors and the same is valid for taxiing systems (which are only activated on ground) [14]

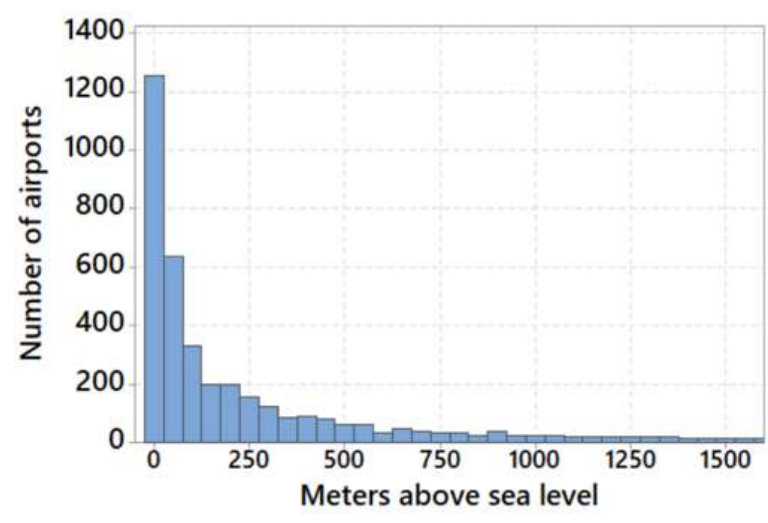

Fig. 2. Altitude above sea level of the busiest airports in the world - data derived from [13].

Electrical machines for aircraft environmental control are installed in a pressurized environment (either in the cabin or in the cargo bay). Their insulation system therefore experiences a limited pressure and temperature swing throughout a standard flight mission. A cross-sectional view of a wide body aircraft is shown in Fig. 3, where the typical pressure and temperature ranges within cabin and cargo bay are reported. In general, the pressurization level is such that even at cruise altitude (i.e. $\approx 13$ $\mathrm{km}$ or 43,000 feet) the actual 'cabin altitude' is maintained at ca. $2.5 \mathrm{~km}$. Similarly, the cabin temperature is controlled to a level slightly above $20{ }^{\circ} \mathrm{C}$, for guaranteeing passengers' 
comfort. A similar scenario is experienced by motors driving fluid and fuel pumps. In this latter case, the pumps can be in most cases totally submerged in the fuel tank [15] and they are fuel-cooled [16]. In a conventional mid-sized aircraft, the fuel tanks are embedded in the wings, whose internal pressure is carefully controlled for avoiding any structural damages.

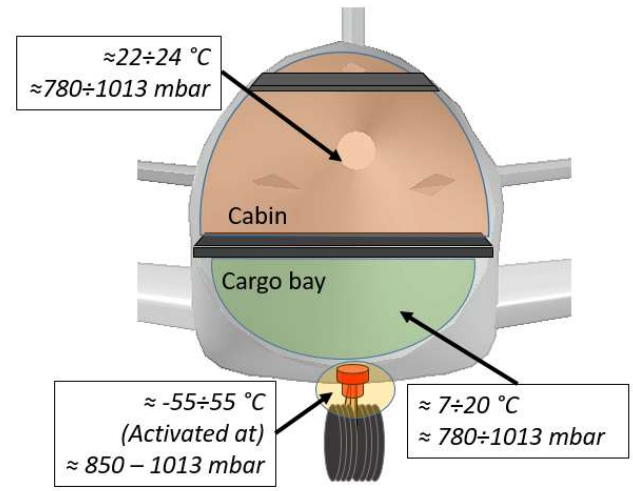

Fig. 3. Typical pressure and temperature inside a wide-body aircraft.

\section{Power Electronics AND Voltage Enhancement}

In electric drives, the voltage amplitude at the machine terminals can be higher than the one at the inverter side due to waveform reflection [17]. This voltage enhancement is contingent on the combination between short rise-time waveforms and long length cables. Transient over-voltages occurring in VSDs can be studied relying on basic transmission line theory and equivalent circuit simulations [18]. For an accurate description of these phenomena, it is required to have a precise knowledge of the motor and cable equivalent impedances as a response to high frequencies impulses. However, it has been widely demonstrated in literature $[4,18]$ and in technical standards [19] that simplified lumped parameter circuital models can precisely estimate the magnitude of the voltage amplification.

The standard IEC 60034-18-41 [19] lists the overvoltage factor $O F$ (i.e. ratio between peak voltage at machine and converter terminals) as a function of the cable length for different rise-times ranging from $50 \mathrm{~ns}$ to $1 \mu \mathrm{s}$. Nonetheless, recent $\mathrm{SiC}$ MOSFETs devices feature times below $50 \mathrm{~ns}$, and the newest ones claim rise-time of $11 \mathrm{~ns}$ [20]. Therefore, relying on a simple lumped parameter circuital model of a transmission line and a load impedance (i.e. machine), the $O F$ has been determined for several cable lengths ranging from 0.1 up to $5.5 \mathrm{~m}$ and four rise-time values, i.e. 10, 20, 30 and $50 \mathrm{~ns}$ as shown in Fig. 4 [7]. The simulations have been performed by assuming a typical three-conductor PVC cable (i.e. velocity factor $\approx 0.5$ ), whilst the motor surge impedance is fixed to $1000 \Omega$, so that a (maximum) 1.9 overvoltage factor is obtained, according to the standard IEC 61800-9, and to existing literature [21]. The system (i.e. cable and motor) is excited with trapezoidal pulses, at the four analysed rise-time levels. The simulated cable - motor configuration emulates an electric drive with a power rating $<90 \mathrm{~kW}$ [21], which covers a large range of machines adopted in a MEA. As the power rating increases, the machine surge impedance decreases, leading to lower overvoltages at its terminals. Thus, the data presented in Fig. 4 account for a near-worst-case scenario. As expected, for a given cable length, the faster is the rise-time the higher is the $O F$.

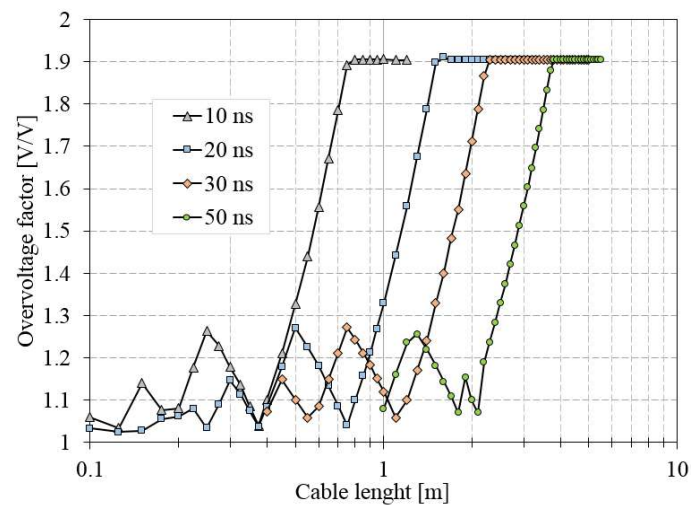

Fig. 4. Overvoltage factor vs. cable length for different rise-times (i.e. 10, 20, 30 and $50 \mathrm{~ns}$ ).

The peak voltage at the machine terminals $V_{p}$ can be calculated as in (1), where $V_{D C}$ is the DC link voltage (voltage drops are neglected because of their modest influence) [6].

$$
V_{p}=V_{D C} \cdot O F
$$

The voltage stressing the turn-to-turn insulation (i.e. the weakest insulation sub-system in a Type-I machine), is strictly related to the rise-time $t_{r}$ of the applied voltage waveform (i.e. the switching time of the power converter) and the relative position of the individual turns within a coil. In a machine powered through a voltage source inverter, for any given DC link voltage, a large fraction of the applied voltage appears across the first coil of a phase winding [22, 23], because of surge (i.e. high frequency voltage components) propagation delay along the winding. As the rise-time of the applied voltage pulses decreases, then the fraction of the phase-to-ground voltage appearing on the initial coil of a winding tends to increase [23-26]. Being Type-I machines generally randomly wound, it is likely that - within a coil - the first turn is in direct contact with the last turn, meaning that the totality of the coil voltage will drop across the interturn insulation [24, 27]. Therefore, the turn-to-turn voltage can be calculated through (2), where $K\left(t_{r}\right)$ is a coefficient whose value is $<1$ [19].

$$
V_{t-t}=K\left(t_{r}\right) \cdot 0.7 \cdot V_{D C} \cdot O F
$$

The " 0.7 " coefficient is semi-empirical, and might, in practice, be higher or lower depending on the grounding system and on the converter's control regime [19]. In the worst-case scenario, i.e. a short $t_{r}$ and the first turn of a coil adjacent to the last one, then $K\left(t_{r}\right)$ can be assumed $\approx 1$. It is worth remarking that (1) and (2) refer to a 2-level inverter whose control algorithm avoids waveform double transitions. In fact, if the converter is not provided with this feature, even higher voltage amplifications can be expected during the transition from a positive to a negative PWM step voltage (and vice-versa).

To achieve for a PD-free turn-to-turn insulation, the voltage level calculated as in (2) must be multiplied by an enhancement factor $E F$, which accounts for insulation aging, harsh environmental conditions and mismatch between partial discharge inception voltage (PDIV) and PD extinction voltage (PDEV). The $E F$ advised in the standard (for qualification tests) [19] can range from 1.25 to 1.63. For PD-safe operations, the PDIV for each insulation subsystem in a machine should be beyond the corresponding (expected) peak voltage, times the $E F$. In this work, only the analysis relative to the turn-to-turn insulation subsystem (i.e. weakest insulation part) will be 
presented. Hence, an inequality can be introduced as expressed by (3) for guaranteeing a PD-free turn-to-turn insulation.

$$
P D I V_{t-t}>V_{t-t} \cdot E F
$$

In Section VI, an experimental investigation on the $E F$ computation for aerospace machines will be presented.

\section{PDIV MODELING}

Various models have been proposed for the PDIV modelling of insulating systems for rotating electrical machines [28-31]. The most widely adopted are those based on the Paschen's law. Although the latter is strictly valid for uniform, (quasi) stationary fields, it is commonly employed for modelling the PD inception in machines' insulation sub-systems [21, 28, 32] and also for the study of other insulation systems for aerospace [33].

Being this paper mainly application-oriented, from a pure engineering perspective, the use of this model represents a fair compromise between accuracy and computational effort. Indeed, the Paschen's model requires just a very limited amount of calculations and analyses, as will be shown in the remainder of this Section. Thus, in this work, the main point of presenting the PDIV computation through the Paschen's curve serves mainly as an aid to machine designers, particularly during the very initial design stage of a newly conceived motor, where a large number of design options need to be apprised. Clearly, the most precise PDIV evaluation is that based on actual measurements carried out on representative specimens and environment, as performed in Section V.

In low voltage random wound machines, the insulation between turns is a thin layer of enamel (e.g. polyamide, polyimide, polyester-imide etc.) and impregnating resin/varnish. Air inclusions between adjacent turns might still exist after the impregnation process and this mainly depends on the impregnation technology/quality. Being the machine randomly wound, it might occur that the first turn of a coil is in direct contact with the last turn (i.e. worst-case), as already discussed in Section III. Thus, the turn insulation must be able to withstand the total coil's voltage, without experiencing PD. In addition, the turn-to-turn voltage can be enhanced by environmental and operating conditions as will be discussed in Sections V and VI. Whilst the actual PDIV under PWM excitation can differ from that predicted through the Paschen's model, the latter is actually valid and shows good results for sinusoidal excitation [7]. This point is extremely important as will be shown in Section V, where the PDIV measurements for sinusoidal and square excitations will be apprised for various ambient pressures.

The implementation of the model for the PDIV estimation between two adjacent turns is illustrated in Fig. 5, were both the Paschen's curve and the voltage drop distribution between the insulated wires are shown. If the curve representing the voltage drop across field lines does not touch or intersect the Paschen's curve, then the applied voltage (between the two turns) is below the PDIV. On the other hand, if the voltage drop curve is tangent (as in the case reported in Fig. 5) or intersects the Paschen's curve, then the applied voltage corresponds to the PDIV or is above the PDIV respectively. The aforementioned PDIV evaluation can be carried out at any pressure level (within the limits of the Paschen's law [34]), by simply normalising the Paschen's curve by the desired pressure level. Indeed, the breakdown voltage is only a function of the product between gap spacing (i.e. field line length) and ambient pressure.

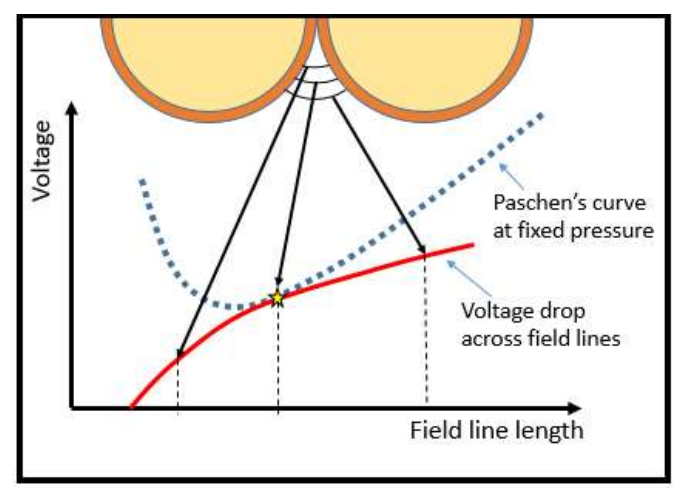

Fig. 5. Computation of the interturn PDIV through Paschen's model.

The voltage drop in the wedge-shaped gap between two adjacent insulated wires can be easily and conveniently estimated through electrostatic FE simulations. Fig. 6 provides an example of FE simulation outcome, where a $0.4 \mathrm{~mm}$ magnet wire with grade 2 insulation (polyamide-imide) is simulated, when a turn-to-turn voltage of $780 V_{\text {peak }}$ is applied. In Fig. 7, the corresponding voltage drop distribution, amongst uniformlyspaced field lines, is plotted alongside with the Paschen's curve, for sea level pressure (i.e. 1013 mbar) and 500 mbar (i.e. $\approx 5.5$ $\mathrm{km}$ altitude) [34]. It can be observed that with this combination of wire diameter, grade and turn-to-turn voltage, there is a risk of PD inception for a gap distance (i.e. electric field line length) of $\approx 30 \mu \mathrm{m}$, at sea level. As the pressure is decreased, a lower applied voltage is sufficient for incepting a PD. For the reported example - namely 500 mbar pressure - the estimated PDIV is $0.61 \mathrm{kV}_{\text {peak. }}$. The curve corresponding to this voltage level does not intercept the Paschen's curve calculated for 1013 mbar pressure, meaning that at sea level there would be no risk of PD inception (for an applied voltage of $0.61 \mathrm{kV}_{\text {peak }}$ ).

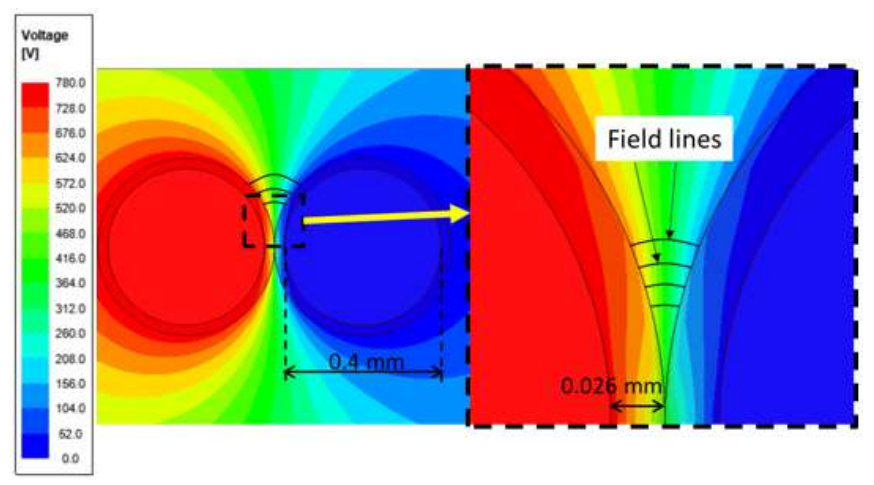

Fig. 6. FE simulation results for $0.4 \mathrm{~mm}, \mathrm{GR} 2$ wire and $V_{\text {peak }}=780 \mathrm{~V}$

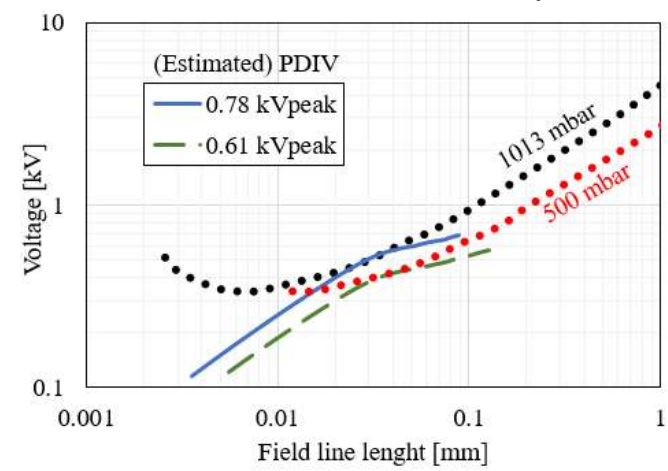

Fig. 7. Voltage drop across field lines and Paschen's curve at sea level pressure and 500 mbar. 


\section{PD ANALySis In REPRESENTATIVE AEROSPACE ENVIRONMENT}

In this Section, the PDIV of winding samples for low voltage, random wound electrical machines is experimentally measured in emulated aerospace environment. The adopted specimens are twisted pairs made of round enameled magnet wire. The reported results refer to a single wire layout, namely a $0.4 \mathrm{~mm}$ diameter, grade 2 magnet wire. Nonetheless, from a qualitative standpoint identical results have been obtained for a large number of tested wire diameters, enamel materials and grades.

The experimental setup employed for the investigation is schematized in Fig. 8 and shown in Fig. 9. A set of five specimens are hung to a PTFE rod and inserted inside an environmental vacuum chamber which allows precise control of temperature and pressure down to $30 \mathrm{mbar}$. The chamber is totally metallic (i.e. stainless steel) except for a $0.062 \mathrm{~cm}^{2}$ glass window, which allows the passage of both electromagnetic waves as well as emitted light. Accordingly, PD detection sensors are placed in direct contact with the window, on the external side of the chamber, at a distance of $\approx 30 \mathrm{~cm}$ from the specimens. Further, black PTFE sheets are used for blocking/shielding any external light from entering the chamber through the remaining, exposed area of the window.

Since the investigation is performed with both sinusoidal as well as square waveforms excitations, the twisted pairs are alternatively fed with a GW Instek ${ }^{\circledR}$ sinusoidal power supply or with a Behlke ${ }^{\circledR}$ high voltage $\mathrm{SiC}$ switch, in push-pull configuration. The latter can apply square waveforms with customizable amplitude, frequency and rise-times down to 10 ns. For the present investigation, the frequency has been set to $2.5 \mathrm{kHz}$, whilst the rise-time has been reduced to the minimum level which guarantees an overshoot-free waveform on the specimen's terminals, namely $150 \mathrm{~ns}$. Unipolar waveforms with negative polarity have been employed.

When the specimens were excited through a sinusoidal waveform, the PDIV was detected through a Hamamatsu ${ }^{\circledR}$ photomultiplier (PMT) connected to a Lecroy ${ }^{\circledR}$ oscilloscope as well as through a transverse electromagnetic antenna with a 100 $\mathrm{MHz}-3 \mathrm{GHz}$ bandwidth, for capturing most of the PD-emitted signal. The antenna is connected to a high-pass analogue filter and to a frequency shifter, so that the signal can be processed through IEC 60270-compliant instrumentation (i.e. Techimp ${ }^{\circledR}$ PD Base II). The acquisition system integrates digital noise rejection features as well as a proprietary PD pattern recognition software.

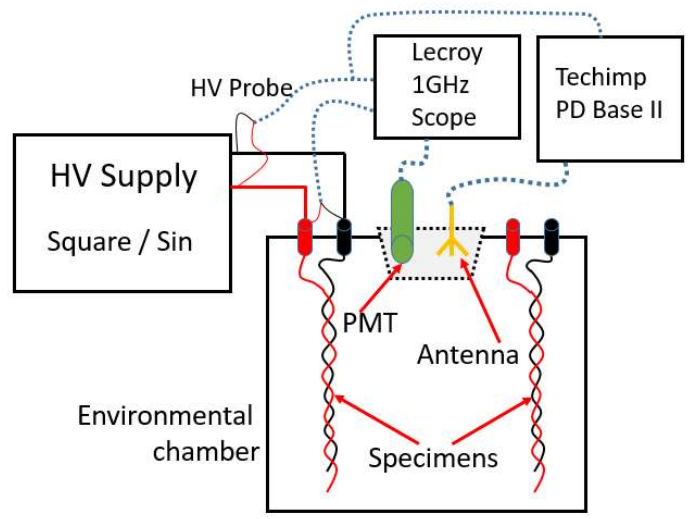

Fig. 8. Scheme of the experimental test setup.

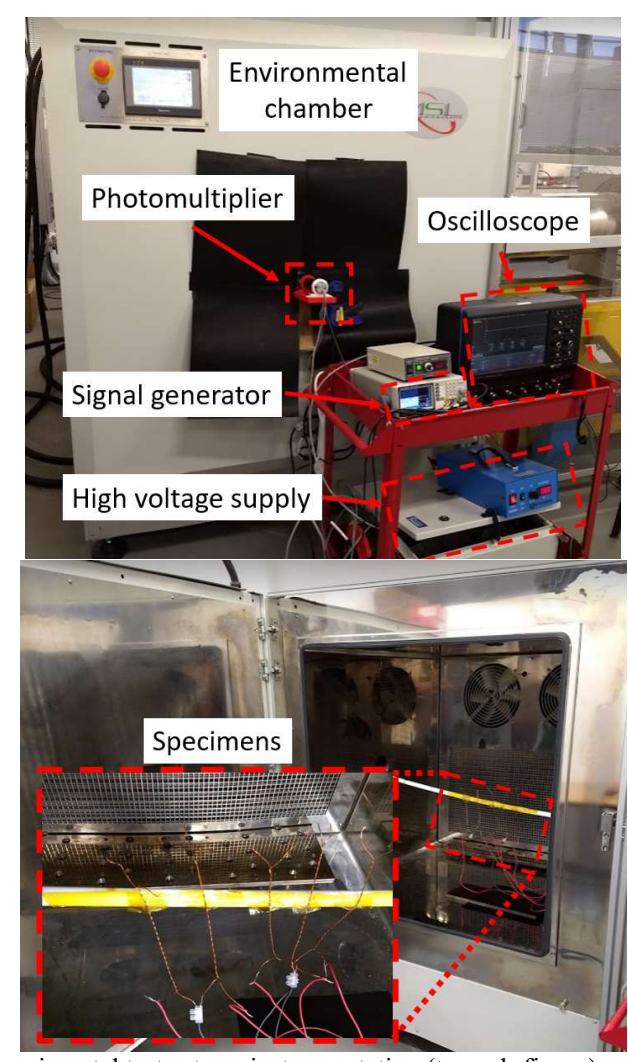

Fig. 9. Experimental test setup - instrumentation (top sub-figure), specimens in environmental chamber (bottom sub-figure).

The system includes a synchronization channel, which is connected to the specimen under test through a high voltage probe. This allows separating PD signals from external electromagnetic disturbances, through classification maps.

When the twisted pairs were excited through a square waveform, only the PMT was used as detection system, since the antenna was highly susceptible to the electromagnetic noise generated by the fast switching $\mathrm{SiC}$ modules. Thus, the measured quantity related to the PD pulses - or "PD magnitude" based on the standard IEC 61934 - is a voltage, which is proportional to the light intensity detected by the PMT. In this case, according to the standard IEC 60034-18-41 the repetitive PDIV (RPDIV) was measured. The RPDIV is defined as the minimum peak-to-peak impulse voltage at which more than five PD pulses occur on ten voltage impulses of the same polarity. This is easily evaluated through the 'Runt Mode' on the oscilloscope.

The tests have been carried out at various pressure levels, starting from sea level, down to 30 mbars (i.e. $>20 \mathrm{~km}$ altitude). The measured RPDIV values have been statistically postprocessed, and the results are summarized in Table I. It is clear that as the pressure decreases so does the RPDIV.

TABLE I. MEASURED RPDIV at VARIOUS PRESSURES (MEDIAN VALUE AND $95 \%$ CONFIDENCE INTERVALS)

\begin{tabular}{|c|c|}
\hline Ambient pressure [mbar] & $\begin{array}{c}\text { RPDIV [kV] } \\
\text { Median and 95\% CI }\end{array}$ \\
\hline 1013 & $1.79[1.76-1.81]$ \\
\hline 500 & $1.49[1.44-1.54]$ \\
\hline 250 & $1.27[1.25-1.29]$ \\
\hline 100 & $1.02[0.96-1.09]$ \\
\hline 50 & $0.91[0.87-0.95]$ \\
\hline 30 & $0.82[0.78-0.75]$ \\
\hline
\end{tabular}




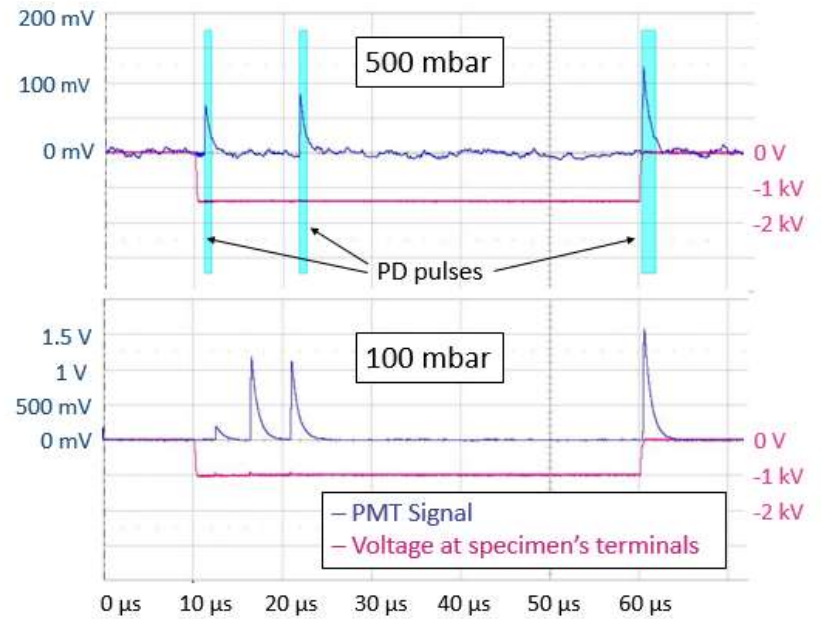

Fig. 10. PMT voltage signals resulting from PD inception.

Fig. 10 shows the time-domain voltage waveform applied to the specimen, as well as the voltage signal from the PMT (i.e. PD magnitude), at two different ambient pressure levels. It can be observed that the rise-time of the PMT signal is much faster than its fall time. This is a general characteristic of voltage output PMT modules, and mainly depends on the internal circuitry of the module, needed for converting a current (charge) - proportional to the light intensity - to a voltage [35]. The green/blue rectangles are introduced for illustrating the working principle of the 'runt mode' on the oscilloscope. Namely, when the PMT signal amplitude is above a pre-defined threshold (i.e. background noise), indicating thus the inception of a PD, then, the oscilloscope a) outlines the PD signals (i.e. green/blue rectangles), and b) stores the information related to these pulses (i.e. number of pulses, amplitude and starting time). Accordingly, this function is helpful in effectively counting the number of PD pulses within a single acquisition time-frame, and thus identifying if the applied voltage is actually the RPDIV.

Although there are no known / standardised methods for correlating the absolute PMT signal (i.e. voltage) amplitude to the 'harmfulness' of a PD, it is fair to state that a high magnitude discharge will result in a stronger light emission, with respect to a lower magnitude one [36-38]. Accordingly, since the PMTdetected signal (i.e. PD magnitude) tends to considerably increase as the pressure decreases (see Fig. 10), then, from a qualitative standpoint, it is fair to state that PD incepted at high altitude might be more harmful than those incepted at ground level. From a pure physics perspective, the decrement of air pressure leads to an increment of mean free path (i.e. average distance travelled by electrons between collisions with air molecules). This means that, at high altitude, the charged particles can acquire more energy under the effect of an applied electric field, thus releasing more energy in the form of light emission when ionizing (i.e. inelastically-colliding with) air molecules. Nonetheless, it is also worthy remarking that TypeI machines must operate free from PD throughout their whole lifetime. It is the task of machine designer and drive integrator to guarantee the fulfillment of this critical condition.

For the sake of representation clarity, the recorded RPDIV values have been normalized with respect to the value obtained at sea level pressure, and they are plotted as histograms in Fig. 11 , where they are also apprised against the PDIV measured under sinusoidal voltage, $50 \mathrm{~Hz}$. Interestingly, it is possible to observe that the normalized (R)PDIV trend with varying altitude, is almost identical for both square and sinusoidal excitations. Although a slight mismatch is noted for pressures of $250 \mathrm{mbar}$ and $50 \mathrm{mbar}$. This result indicates that, in principle, the PDIV measurement at low pressure can be carried out though a simple sinusoidal excitation which surely represents less of a burden in practical terms (i.e. simpler, and well assessed PD detection techniques), and provides a conservative PDIV figure. Further, the above suggests that, for an initial evaluation, the Paschen's model discussed in Section IV (which shows accurate results for sinusoidal excitation) can be actually employed. However, it is important to note that, for a given specimen, in terms of absolute value the (square) RPDIV and the (sinusoidal) PDIV can considerably differ, as one can note from the base normalization voltages in Fig. 11, and thus, for precise evaluations, experimental tests need to be performed.

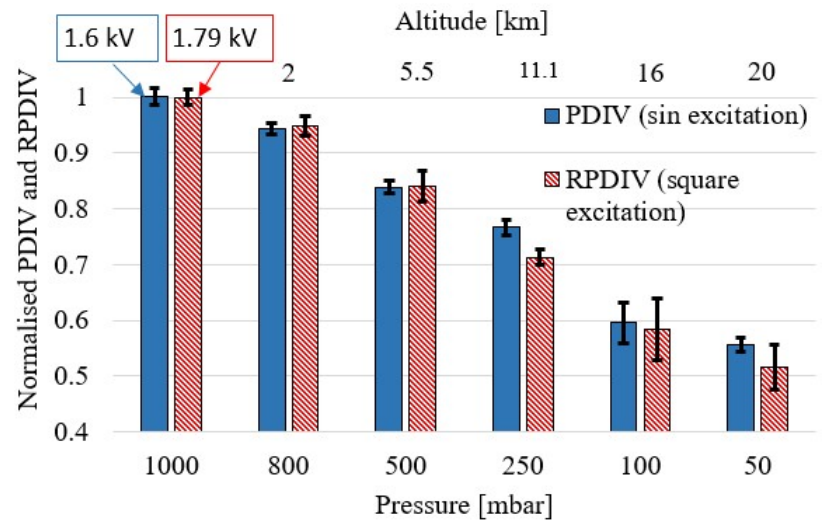

Fig. 11. (R)PDIV at various pressures, normalized to sea level condition.

\section{PD ENHANCEMENT FACTORS EVALUATION}

\section{A. On the Temperature Influence and Thermal Aging}

The standard IEC 60034-18-41 suggests (for type tests) the use of a safety factor (see Section III) of 1.3 which accounts for the (R)PDIV variation (i.e. decrement) with increasing operating temperature and a factor of 1.2 for the aging.

Actuators for flight control surfaces in aircraft are considered as safety-critical, since a failure might endanger human lives. This also means that any machine driving such an actuator must at any point throughout its lifetime have an extremely high reliability level (a typical failure rate for a safety-critical aerospace system is $10^{-9}$ failures per flight hour, or less). For fulfilling such a stringent reliability constrain, fault-tolerant drive topologies are often implemented. At the same time, the motor is thermally designed for limiting as much as possible the detrimental effect of thermal aging, whilst avoiding any strong over-engineering [39]. Thus, it is unlikely that an aerospacegrade machine will experience any extreme thermal aging, throughout its operational life, able to have a considerable influence on its insulation system's PDIV [40]. This indicates that it is fair, for safety-critical aerospace machines, to assume a negligible thermal aging throughout their operational life. 
This also implies that the PD enhancement factor of 1.2 indicated in the standard [19] could be avoided for aerospacegrade machines.

For what concerns the instantaneous operating temperature influence on the PDIV decrement, again, the enhancement factor of 1.3 proposed in [19] for ground based motors, should be revised for aerospace counterparts. The variation of PDIV with temperature has been experimentally investigated through a thermal environmental chamber and winding specimens, and the results are summarized in Fig. 12. A linear model appropriately interpolates the experimentally recorded data, and the fitting equation is also reported in Fig. 12. For the considerations discussed above (regarding thermal aging), it is highly likely that the insulation for a class 200 motor would operate well below its actual thermal class.

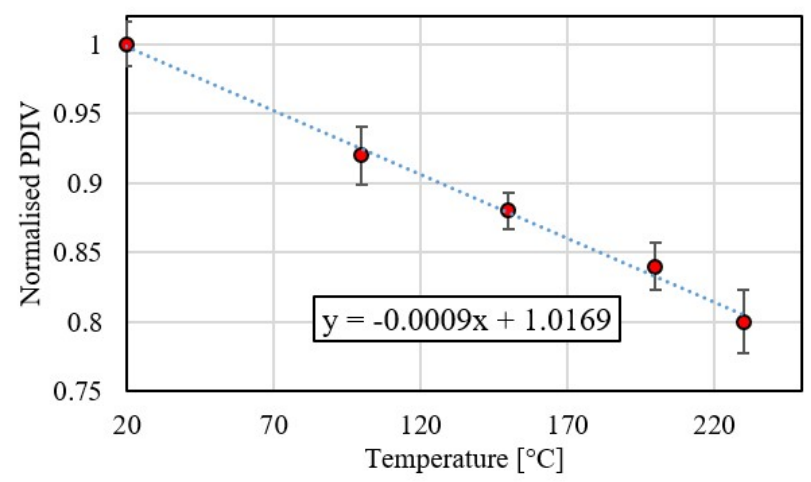

Fig. 12. PDIV variation with temperature at sea level pressure.

Assuming a worst-case maximum ambient temperature of $\approx 40$ $50{ }^{\circ} \mathrm{C}$ (e.g. aircraft stationary on a hot runaway), this means that the machine should be thermally designed for a maximum temperature rise $<150{ }^{\circ} \mathrm{C}$ (i.e. worst-case winding hot-spot temperature $<200{ }^{\circ} \mathrm{C}$ ).

A new PDIV temperature correction factor can be thus introduced based on Fig. 12's findings, for machines operating in a MEA, according to the actual winding temperature rise. Clearly, the temperature rise needs to be linked to the international standard atmosphere (ISA) reported in Fig. 13, for machines installed in unpressurised aircraft sections.

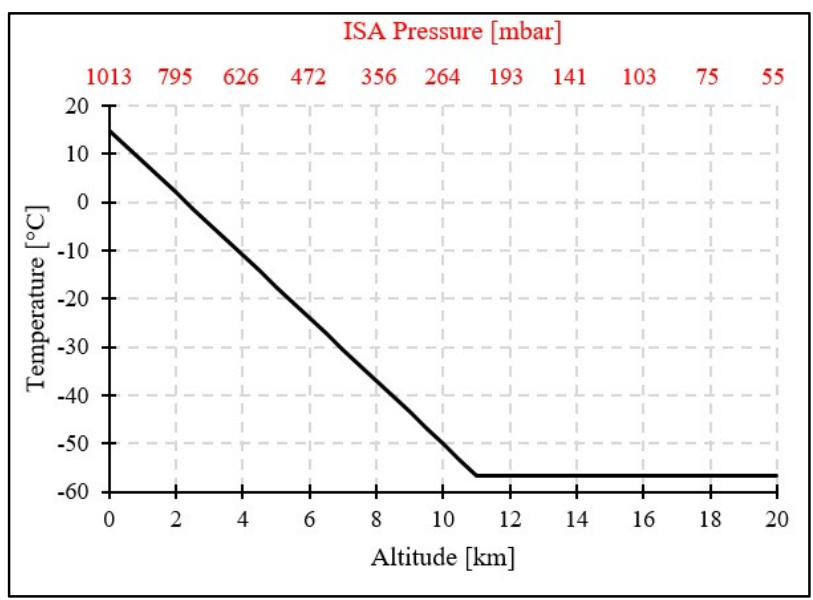

Fig. 13. International Standard Atmosphere.

\section{B. PD Safety Factor}

An additional term contributing to the PD enhancement factor computation (see (3)) is generally introduced for both qualification and type tests of insulation systems for Type-I insulation systems. Its value is fixed to 1.25 and accounts for the discrepancy (i.e. hysteresis effect) between RPDIV and PDEV, namely, the voltage at which partial discharges are extinguished in the test arrangement. This is measured by gradually decreasing the voltage applied to the test object from a higher value at which PD are observed.

The PDEV has been measured for a set of 5 twisted pair specimens at various environmental pressures and fixed temperature of $20^{\circ} \mathrm{C}$, and the statistically-processed results are presented in Table II. The results refer to square waveform excitation, as reported in Section V. On average, the PDEV is 0.89 times lower than the RPDIV. Therefore, the enhancement factor of 1.25 might be appropriate in this case, although slightly conservative (i.e. $0.89 \cdot 1.25>1$ ).

TABLE II. MEASURED PDEV at VARIOUS PRESSURES (MEDIAN VALUE AND 95\% CONFIDENCE INTERVALS)

\begin{tabular}{|c|c|}
\hline Ambient pressure [mbar] & $\begin{array}{c}\text { PDEV [kV] } \\
\text { Median and 95\% CI }\end{array}$ \\
\hline 1013 & $1.64[1.60-1.68]$ \\
\hline 500 & $1.35[1.33-1.36]$ \\
\hline 250 & $1.14[1.11-1.18]$ \\
\hline 100 & $0.87[0.88-0.92]$ \\
\hline 50 & $0.79[0.74-0.82]$ \\
\hline 30 & $0.72[0.70-0.74]$ \\
\hline
\end{tabular}

The normalized RPDIV at various pressures (i.e. altitudes) can be then 'corrected' according to both temperature and PD safety factors. This is done in Fig. 14, where the RPDIV temperature correction is performed according to the findings of Fig. 12 assuming a winding temperature rise of $150{ }^{\circ} \mathrm{C}$ above the ISA conditions, and a PD safety factor of 0.89 is used.

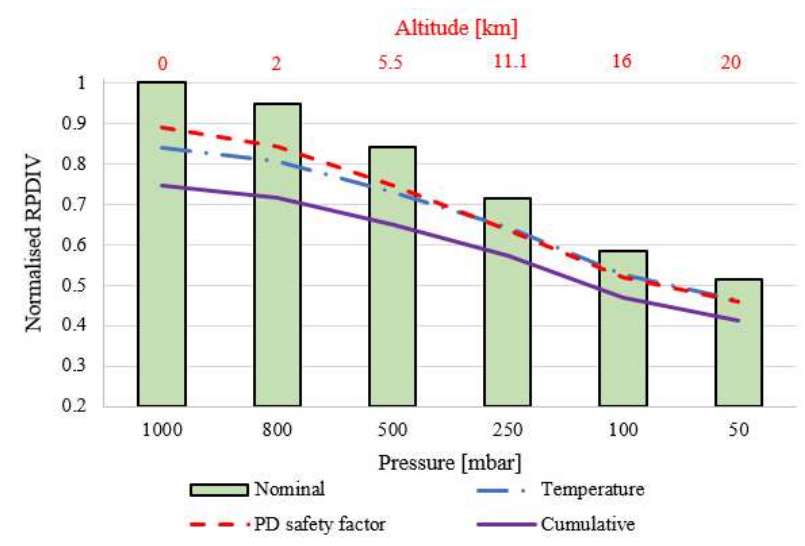

Fig. 14. RPDIV vs. pressure (i.e. altitude) including correction factors.

\section{IMPLICATIONS ON THE DESIGN OF AEROSPACE MACHINES}

At this point, it is possible to carry out a comprehensive discussion by summarizing the data presented throughout the paper and providing considerations from a motor design standpoint. For doing so, Fig. 15 is introduced, where the RPDIV vs. altitude is plotted, together with the typical altitude ranges encountered throghout a flight mission of a commercial aircraft. According to the analysis reported in Section II, it is 
clear that aerospace machines installed in pressurised, controlled environment (e.g. for environmental control, fluid and fuel pumps) can be designed similarly to their ground based counterparts (e.g. industrial or automotive machines). Indeed, they will never experience extreme ambient pressures throghout their lifetime. Nonetheless, particular care must be taken for guaranteing appropriate reliability levels by focusing on insulation stresses such as thermal and mechanical (i.e. vibrations), but this is not discussed within this manuscript.

A similar operating condition is experienced by landing gear actuation and electric taxiing machines. Even in these cases, the influence of ambient pressure on PD inception can be neglected, given the relatively low activation altitude, as clearly indicated by the data in Fig. 2. However, in this case, since the machine is mainly activated at low altitude (i.e. high pressure, but also a relatively high temperature), the ambient temperature can play a considerable role on the RPDIV reduction (up-to $\approx 20 \%$, according to Fig. 14).

Electromechanical actuators for secondary flight control surfaces are activated up-to altitudes of ca. $6 \mathrm{~km}$ (see Section II). In this case the variation of ambient pressure starts to have a slight influence on the RPDIV, but at the same there is also a beneficial cooling effect, thanks to the relatively low ambient temperature (see Fig. 13). Considering the cumulative effect of pressure variation and the PD safety factors discussed in Section VI, the interturn insulation system for a flap actuator machine (i.e. secondary flight control surface) can have an interturn RPDIV value which is $\approx 0.6 \div 0.7$ times lower than that of an identical motor designed to operate at sea level pressure.

The most critical machines are thus those actuating primary flight control surfaces (e.g. rudder, elevator etc...). In this case, given that these can be operated up-to cruise altitude, there is a strong influence of ambient pressure on the interturn RPDIV. Even the potential benefits of an enhanced cooling are eclipsed by the strong RPDIV reduction caused by the lower pressure.

According to the discussion in Section III, and in particular Fig. 4 , it is clear that for a fixed DC link voltage, converter risetime (i.e. fixed $\mathrm{dV} / \mathrm{dt}$ ) and machine surge impedance, the longer is the connection cable (between machine and converter) the higher will be the over-voltage at the machine terminals. Therefore, adopting an integrated drive (i.e. a short connection cable) can be a suitable methodology for reducing this overvoltage, also considering the progressive push towards even-faster switching power modules and higher operating voltages in aerospace [41, 42].

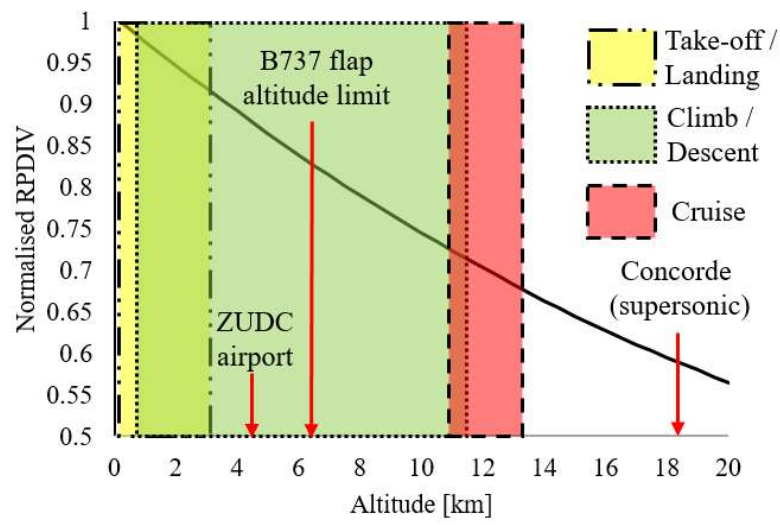

Fig. 15. RPDIV trend throughout various flight stages (ZUDC: airport with the highest altitude above sea level in the world)
For wrapping up, the impact of the operating environment on the PD inception in aerospace machines is qualitatively illustrated in Table III, which is compiled according to all the analyses presented throghout this work, and summarised in this Section.

TABLE III. IMPACT OF PRESSURE AND TEMPERATURE ON PDIV IN MEA MACHINES ('++' STRONG IMPACT; '+' MINIMUM IMPACT; '-' NO IMPACT)

\begin{tabular}{|c|c|c|}
\hline Machine Application & $\begin{array}{c}\text { Pressure } \\
\text { variation }\end{array}$ & $\begin{array}{c}\text { Temperature } \\
\text { variation }\end{array}$ \\
\hline Primary actuators & ++ & + \\
\hline Secondary actuators & + & + \\
\hline Fuel pumps & + & + \\
\hline $\begin{array}{c}\text { Environmental control } \\
\text { compressors / fans }\end{array}$ & - & - \\
\hline Fluid pumps & - & - \\
\hline Landing gear actuators & - & ++ \\
\hline Electric taxiing & - & ++ \\
\hline
\end{tabular}

\section{CONCLUSIONS}

This paper presented an application-oriented investigation into the problem of partial discharges in electrical machines for the more electric aircraft. The actual operating environment experienced by machines employed in a typical commercial aircraft has been firstly identified and then employed for an extensive experimental investigation. It has been verified that the variation of environmental conditions (i.e. pressure and temperature) throughout a flight mission can strongly influence the PD inception voltage in machines' insulation systems.

In particular, it has been demonstrated that the ambient pressure variation from sea level to cruise altitude can reduce the PD inception voltage by a factor of 0.7 , or more. From a qualitative stand-point, the measured PD inception voltage under sinusoidal excitation follows the same trend as the one measured under square excitation. Thus, for an initial evaluation, the PD inception voltage can be estimated through the well-assessed Paschen's model (valid for quasi-stationary fields), combined with finite element simulations, whose results showed a good agreement with the experimental findings.

Amongst all the analysed aerospace machines, in this work it has been demonstrated that particular care must be taken when designing machines actuating primary flight control surfaces. These are installed in unpressurised sections of the aircraft and activated up-to cruise altitude (i.e. extremely low pressures). On the contrary, machines installed in the cabin, cargo bay and fuel tanks do not experience excessive pressures and temperature swings throughout a flight, and thus their design of insulation can be carried out as done for ground-based, safety-critical machines. A similar design approach can be employed for actuator machines for secondary flight control, electric taxiing and landing gears. In these cases, it is mainly the winding temperature increment which can causes a decrement of PD inception voltage, rather than the variation in ambient pressure.

\section{REFERENCES}

[1] A. Cavallini, "Reliability of low voltage inverter-fed motors: What have we learned, perspectives, open points," in 2017 International Symposium on Electrical Insulating Materials (ISEIM), 2017, vol. 1, pp. 13-22.

[2] S. B. Lee, A. Naeini, S. Jayaram, G. C. Stone, and M. Šašić, "Surge TestBased Identification of Stator Insulation Component With Partial 
Discharge Activity for Low Voltage AC Motors," IEEE Transactions on Industry Applications, vol. 56, no. 3, pp. 2541-2549, 2020.

[3] M. Ghassemi, "Accelerated insulation aging due to fast, repetitive voltages: A review identifying challenges and future research needs," IEEE Transactions on Dielectrics and Electrical Insulation, vol. 26, no. 5, pp. 1558-1568, 2019.

[4] B. Taghia, B. Cougo, H. Piquet, D. Malec, A. Belinger, and J.-P. Carayon, "Overvoltage at motor terminals in SiC-based PWM drives," Mathematics and Computers in Simulation, 2018/09/27/ 2018.

[5] W. Cao, B. C. Mecrow, G. J. Atkinson, J. W. Bennett, and D. J. Atkinson, "Overview of Electric Motor Technologies Used for More Electric Aircraft (MEA)," IEEE Transactions on Industrial Electronics, vol. 59, no. 9, pp. 3523-3531, 2012.

[6] P. Mancinelli, S. Stagnitta, and A. Cavallini, "Qualification of Hairpin Motors Insulation for Automotive Applications," IEEE Transactions on Industry Applications, vol. 53, no. 3, pp. 3110-3118, 2017.

[7] V. Madonna, P. Giangrande, W. Zhao, H. Zhang, C. Gerada, and M. Galea, "On the Design of Partial Discharge-Free Low Voltage Electrica Machines," in 2019 IEEE International Electric Machines \& Drives Conference (IEMDC), 2019, pp. 1837-1842.

[8] T. J. Hammarstroem, "A General Measurement Set-up Approach to Evaluate Insulation System Quality by Exploring PWM and DC biased waveforms," IEEE Transactions on Industry Applications, pp. 1-1, 2020.

[9] M. Szczepanski, D. Malec, P. Maussion, and P. Manfé, "Design of Experiments Predictive Models as a Tool for Lifespan Prediction and Comparison for Enameled Wires Used in Low-Voltage Inverter-Fed Motors," IEEE Transactions on Industry Applications, vol. 56, no. 3, pp 3100-3113, 2020

[10] C. Abadie, T. Billard, and T. Lebey, "Partial Discharges in Motor Fed by Inverter: From Detection to Winding Configuration," IEEE Transactions on Industry Applications, vol. 55, no. 2, pp. 1332-1341, 2019.

[11] D. Roger, S. Ait-Amar, E. Napieralska-Juszczak, and P. Napieralski, "Proposition for Improving the Design of Motor Windings for LowPressure Environment," IEEE Transactions on Industry Applications, vol. 56, no. 3, pp. 2491-2499, 2020.

[12] D. R. Meyer, A. Cavallini, L. Lusuardi, D. Barater, G. Pietrini, and A. Soldati, "Influence of impulse voltage repetition frequency on RPDIV in partial vacuum," IEEE Transactions on Dielectrics and Electrical Insulation, vol. 25, no. 3, pp. 873-882, 2018.

[13] "Available: https://openflights.org/data.html," ed.

[14] M. Lukic, P. Giangrande, A. Hebala, S. Nuzzo, and M. Galea, "Review, Challenges, and Future Developments of Electric Taxiing Systems," IEEE Transactions on Transportation Electrification, vol. 5, no. 4, pp. 14411457, 2019.

[15] "Available: https://ph.parker.com/us/17579/en/aerospace-fuel-pumpsfsd," ed.

[16] I. Moir and A. Seabridge, Aircraft systems: mechanical, electrical, and avionics subsystems integration. John Wiley \& Sons, 2011.

[17] R. Kerkman, D. Leggate, and G. Skibinski, "Interaction of drive modulation and cable parameters on AC motor transients," in IAS '96. Conference Record of the 1996 IEEE Industry Applications Conference Thirty-First IAS Annual Meeting, 1996, vol. 1, pp. 143-152 vol.1.

[18] E. Persson, "Transient effects in application of PWM inverters to induction motors," IEEE Transactions on Industry Applications, vol. 28, no. 5, pp. 1095-1101, 1992.

[19] IEC 60034-18-41:2014 Rotating electrical machines - Part 18-41: Partial discharge free electrical insulation systems (Type I) used in rotating electrical machines fed from voltage converters - Qualification and quality control tests 2014

[20] CREE. E3M0065090D Datasheet, Available: https://www.wolfspeed.com/downloads/dl/file/id/1305/product/358/e3m0 065090d.pdf.

[21] H. Okubo, N. Hayakawa, and G. C. Montanari, "Technical Development on Partial Discharge Measurement and Electrical Insulation Techniques for Low Voltage Motors Driven by Voltage Inverters," IEEE Transactions on Dielectrics and Electrical Insulation, vol. 14, no. 6, pp. 1516-1530, 2007.

[22] Y. Xie, J. Zhang, F. Leonardi, A. R. Munoz, M. W. Degner, and F. Liang, "Voltage Stress Modeling and Measurement for Random-Wound Machine Windings Driven by Inverters," IEEE Transactions on Industry Applications, vol. 56, no. 4, pp. 3536-3548, 2020.

[23] G. Stone, S. Campbell, and S. Tetreault, "Inverter-fed drives: which motor stators are at risk?," IEEE Industry Applications Magazine, vol. 6, no. 5 , pp. 17-22, 2000 .
[24] P. Bidan, T. Lebey, G. Montseny, and J. Saint-Michel, "Transient voltage distribution in inverter fed motor windings: experimental study and modeling," IEEE Transactions on Power Electronics, vol. 16, no. 1, pp. 92-100, 2001.

[25] R. Acheen, C. Abadie, T. Billard, T. Lebey, and S. Duchesne, "Study of partial discharge detection in motors fed by SiC MOSFET and Si IGBT inverters," in 2019 IEEE Electrical Insulation Conference (EIC), 2019, pp. 497-500.

[26] M. Melfi, A. M. J. Sung, S. Bell, and G. L. Skibinski, "Effect of surge voltage risetime on the insulation of low-voltage machines fed by PWM converters," IEEE Transactions on Industry Applications, vol. 34, no. 4, pp. 766-775, 1998.

[27] M. K. W. Stranges, G. C. Stone, and D. L. Bogh, "New specs for ASD motors," IEEE Industry Applications Magazine, vol. 13, no. 1, pp. 37-42, 2007.

[28] G. C. Montanari, P. Seri, and G. Stone, "Prospects for increasing supply voltage and design of electrical field rotating machine windings supplied from power electronics," IEEE Electrical Insulation Magazine, vol. 36, no. 3, pp. 31-38, 2020.

[29] L. Lusuardi, A. Cavallini, M. G. d. 1. Calle, J. M. Martínez-Tarifa, and G. Robles, "Insulation design of low voltage electrical motors fed by PWM inverters," IEEE Electrical Insulation Magazine, vol. 35, no. 3, pp. 7-15, 2019.

[30] N. Driendl, F. Pauli, and K. Hameyer, "Modeling of Partial Discharge Processes in Winding Insulation of Low-Voltage Electrical Machines Supplied by High $\$ \backslash$ mathrm $\{\mathrm{du}\} \wedge$ mathrm $\{\mathrm{dt}\} \$$ Inverters," in IECON 2019 - 45th Annual Conference of the IEEE Industrial Electronics Society, 2019, vol. 1, pp. 7102-7107.

[31] M. Borghei, M. Ghassemi, J. M. Rodriguez-Serna, and R. Albarracin, "A Finite-Element-Analysis and an Improved Induced Charge Concept for Partial Discharge Modeling," IEEE Transactions on Power Delivery, pp. $1-1,2020$.

[32] T. Mathurin, S. Duchesne, and G. Parent, "Assessment of finite element simulation methodologies for the use of Paschen's law in the prediction of partial discharge risk in electrical windings," IEEE Access, pp. 1-1, 2020.

[33] I. Cotton, A. Nelms, and M. Husband, "Higher voltage aircraft power systems," IEEE Aerospace and Electronic Systems Magazine, vol. 23, no. 2, pp. 25-32, 2008.

[34] T. W. Dakin et al., "Breakdown of gases in uniform fields," Proc. Int. Conf. Large High Voltage Electric Systems, CIGRE, SC 15, pp. 1-42, 1977.

[35] Hamamatsu, "Photomultiplier Tubes, Basics and Applications, Third Edition - $\quad$ Available: https://www.hamamatsu.com/resources/pdf/etd/PMT handbook_v3aE.p df," ed.

[36] N. Hayakawa, F. Shimizu, and H. Okubo, "Estimation of partial discharge inception voltage of magnet wires under inverter surge voltage by volumetime theory," IEEE Transactions on Dielectrics and Electrical Insulation, vol. 19, no. 2, pp. 550-557, 2012.

[37] K. Kimura, S. Ushirone, T. Koyanagi, and M. Hikita, "PDIV characteristics of twisted-pair of magnet wires with repetitive impulse voltage," IEEE Transactions on Dielectrics and Electrical Insulation, vol. 14, no. 3, pp. 744-750, 2007.

[38] N. Hayakawa and H. Okubo, "Partial discharge characteristics of inverterfed motor coil samples under ac and surge voltage conditions," IEEE Electrical Insulation Magazine, vol. 21, no. 1, pp. 5-10, 2005.

[39] P. Giangrande, V. Madonna, S. Nuzzo, and M. Galea, "Moving Toward a Reliability-Oriented Design Approach of Low-Voltage Electrical Machines by Including Insulation Thermal Aging Considerations," IEEE Transactions on Transportation Electrification, vol. 6, no. 1, pp. 16-27, 2020.

[40] V. Madonna, P. Giangrande, G. Migliazza, G. Buticchi, and M. Galea, "A Time-Saving Approach for the Thermal Lifetime Evaluation of LowVoltage Electrical Machines," IEEE Transactions on Industrial Electronics, vol. 67, no. 11, pp. 9195-9205, 2020.

[41] J. K. Nøland, M. Leandro, J. A. Suul, and M. Molinas, "High-Power Machines and Starter-Generator Topologies for More Electric Aircraft: A Technology Outlook," IEEE Access, vol. 8, pp. 130104-130123, 2020.

[42] V. Madonna, G. Migliazza, P. Giangrande, E. Lorenzani, G. Buticchi, and M. Galea, "The Rebirth of the Current Source Inverter: Advantages for Aerospace Motor Design," IEEE Industrial Electronics Magazine, vol. 13, no. 4 , pp. $65-76,2019$. 